PACS 92.40.Cy, 47.55.Mh

\title{
THE MATHEMATICAL MODELLING OF RADIONUCLIDE TRANSPORT IN THE SUBSURFACE ENVIRONMENT AROUND THE CHORNOBYL NUCLEAR POWER PLANT
}

\author{
S.L.KIVVA \\ Institute of Mathematical Machines \& Systems Problems \\ of the Ukrainian National Academy of Sciences \\ 42 Glushkova Av., UA-252187 Kyiv, Ukraine
}

Received September 18, 1997

\begin{abstract}
The Shelter constructed above the destroyed Unit-4 of the Chornobyl Nuclear Power Plant contains $20 \mathrm{MCi}$ of nuclear fuel. More than $1000 \mathrm{~m}^{3}$ of intermediate-level radioactive water is disposed in its basement. The purpose of this work is to simulate migration of the radionuclides ${ }^{90} \mathrm{Sr}$ and ${ }^{137} \mathrm{Cs}$ from the Shelter into the subsurface environment to evaluate their migration rate and migration paths. A mathematical model accounting for the coupled transport of water and radionuclides in variably saturated media is used. The lack of suitable experimental and field studies excluded the possibility of complete validating the model. Results of the simulations will be useful for future studies of the environmental impact of the Shelter.
\end{abstract}

\section{Introduction}

A Shelter containment structure constructed upon the ruins of the destroyed reactor building of the Chornobyl Unit-4 was completed in November 1986. This containment was built in very high radioactive fields in the short time span of six months by using unique and remote construction methods. However, these remote methods for pouring fresh concrete did not always permit good observation and view of work, and in a number of cases high radioactive fields made welding key containment components impossible. As a result of this, openings and breaks in the walls and the roof of the Shelter are estimated to total about $1200 \mathrm{~m}^{2}$.

By current estimates, the Shelter contains from 135 to 180 tons of nuclear fuel with an activity of up to $20000000 \mathrm{Ci}$ [1]. Within the Shelter the largest part of the nuclear fuel from the completely destroyed reactor core is contained in fuel-containing materials (FCM), and the rest - in fuel assemblies and their fragments. The FCM can be represented as lava-like materials with a glass silicate matrix containing many inclusions of various uranium compounds, finely dispersed high-level active fuel dust, and aerosols. Experimental observations show a gradual increase in the migration rate of radionuclides from the FCM caused by their permanent interaction with the water and atmosphere inside the Shelter. Contamination of the environment by radioactive substances from the Shelter may occur in two principal ways: (1) release of fuel dust into the atmosphere through the openings in the Shelter if there is a collapse of internal structures within the Shelter, and (2) migration of radionuclides through the subsurface together with the water which is inside the Shelter.

(C) S.Kivva, 1997

ISSN 0452-9910. Condensed Matter Physics 1997 No 12 (121-131) 
According to previous research $[2,3]$ the Shelter contains more than 3000 $\mathrm{m}^{3}$ of intermediate-level and low-level radioactive water. More than 1000 $\mathrm{m}^{3}$ of intermediate-level radioactive water is disposed in the basement of Unit-4. Most of the contaminated water is located in the turbo-generator hall and rooms on the first level in the northern part of the Shelter [4] (see figure 1). It is also reasonable to consider such major water sources within

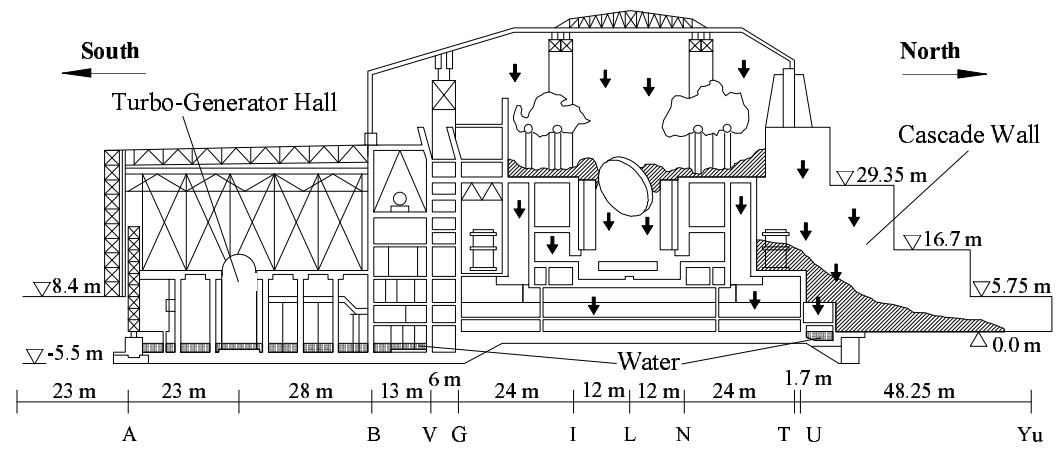

Figure 1. Schematic representation of the Chornobyl Unit-4 Shelter, water pathways and locations within the Shelter. North-south cross-section along Axis 47.

the Shelter as: precipitation, water used for dust suppression, moisture condensation onto building structures, and water leakage from the service lines of the 3rd unit of the Chornobyl NPP. Most precipitation onto the roof penetrates through cracks to the interior of the Shelter. The volume of this precipitation is approximately $1000 \mathrm{~m}^{3}$ per year. For dust suppression, $15 \mathrm{~m}^{3}$ of water are sprayed twice a month within the Shelter. Water enters the Shelter through the above mentioned openings and flows downwards into the lower regions of the reactor building where most of the fuel is located. Upon movement through the FCM and interaction with them, the water is contaminated by radionuclides. The contaminated water penetrates into the subsurface environment. The total activity of the intermediate-level radioactive water lies within the range of $2 \times 10^{12}$ to $9 \times 10^{13} \mathrm{~Bq} / \mathrm{l}$. Cesium isotopes constitute the main portion of the water activity; the cesium activity varies from $1.6 \times 10^{5}$ to $5.5 \times 10^{7} \mathrm{~Bq} / \mathrm{l}$. The total ${ }^{90} \mathrm{Sr}$ activity in the water was determined to be $3.6 \times 10^{3}$ to $1.1 \times 10^{6} \mathrm{~Bq} / \mathrm{l}$.

The Chornobyl NPP is located on the right bank of the Prypiat river. The NPP site is a flat river bench. The aquifer system is composed of fine, medium and sometimes coarse alluvial sands with interlayers of sand loam and loam. Medium sands prevail. According to field studies the hydraulic conductivity of the alluvial sands ranges from 6.0 to $15.0 \mathrm{~m} \mathrm{day}^{-1}$. These alluvial sands the thickness of which varies from 25 to $40 \mathrm{~m}$ are underlain by clay marls of the Kyiv Eocene suite. The marls have very low permeability and act as an aquitard. The infiltration is estimated between $80 \mathrm{~mm}$ and $200 \mathrm{~mm}$ per year [5].

The purpose of this work is to simulate migration of ${ }^{90} \mathrm{Sr}$ and ${ }^{137} \mathrm{Cs}$ through geologic media due to different scenarios of water leakage from the Shelter. 


\section{Model description}

\subsection{Water flow equations}

Mathematical description of water transport in a variably saturated subsurface implies assumptions which are commonly done for this type of problems. It is assumed that fluid transport through the soil occurs in response to pressure gradients and gravitational body forces following Darcy's flow equations. The porous medium is considered to be rigid. Pressure gradients in the gas phase are so negligible that gas pressure remains effectively constant at the atmospheric pressure.

Neglecting hysteresis and temperature gradients, the movement of moisture through a saturated-unsaturated porous medium is described by

$$
\frac{\partial}{\partial t}(\phi S \rho)=\frac{\partial}{\partial x_{i}}\left[\frac{\rho k_{r} k_{i j}}{\mu}\left(\frac{\partial p}{\partial x_{j}}+\rho g \frac{\partial z}{\partial x_{j}}\right)\right]+f,
$$

where $t$ is the time $(T) ; x_{i}$ are the cartesian spatial coordinates $(L) ; \phi$ is the porosity of the medium; $\rho$ is the fluid density $\left(M L^{-3}\right) ; k_{i j}$ are components of the intrinsic permeability tensor $\left(L^{2}\right) ; k_{r}$ is the relative permeability $\left(0 \leqslant k_{r} \leqslant 1\right) ; \mu$ is the fluid dynamic viscosity $\left(M L^{-1} T^{-1}\right) ; p$ is the fluid pressure $\left(M L^{-1} T^{-2}\right) ; g$ is the gravitational constant $\left(L T^{-2}\right) ; z$ is the elevation measured from a reference datum $(L) ; f$ represents sources or sinks of fluid in the system $\left(M L^{-3} T^{-1}\right)$; and $S$ is the volumetric saturation.

Initial conditions for equation (2.1) consist of initial values of pressure, specified by

$$
p(x, 0)=\varphi(x),
$$

where $x$ is a spatial coordinate vector and $\varphi$ is a prescribed function.

Boundary conditions may be Dirichlet (type 1):

$$
p(x, t)=g_{1}(x, t) \quad \text { on } \quad \Gamma_{1},
$$

or Neumann (type 2):

$$
\left[k_{r} \frac{k_{i j}}{\mu}\left(\frac{\partial p}{\partial x_{j}}+\rho g \frac{\partial z}{\partial x_{j}}\right)\right] n_{i}=g_{2}(x, t) \quad \text { on } \quad \Gamma_{2},
$$

where $g_{1}$ is the prescribed pressure on the boundary $\Gamma_{1} ; n_{i}$ is the $i$ th component of the unit vector normal to the boundary $\Gamma_{2}$, directed outward; and $g_{2}$ is the prescribed outward fluid flux normal to $\Gamma_{2} . \Gamma_{1}$ and $\Gamma_{2}$ comprise the entire boundary of the domain. Usually $\Gamma_{1}$ is the part of boundary at which surface-water bodies are intercepted by aquifers; $\Gamma_{2}$ are the boundaries across which fluid passes at a specific rate (impervious boundaries, areas of infiltration or evapotranspiration, points of injection and withdrawal, etc.).

\subsection{Transport equations}

Let $c_{l}$ represent the volumetric radionuclide activity in the aqueous phase $\left(M L^{-3}\right) ; c_{s}$ - the volumetric exchangeable sorbet activity in the solid phase $\left(M L^{-3}\right)$; and $c_{f}$ - the volumetric radionuclide activity which is fixed in the mineral lattice $\left(M L^{-3}\right)$. Assuming that the ion-exchange reaction transferring activity between aqueous and solid exchangeable phases has a sufficiently short timescale, we will consider this reaction as instantaneous which 
is described by a linear equilibrium isotherm. Transfers of activity to and from the fixed phase are modelled by first-order rate constants $\alpha_{s f}$ and $\alpha_{f s}$, respectively, as shown in figure $2[6]$.

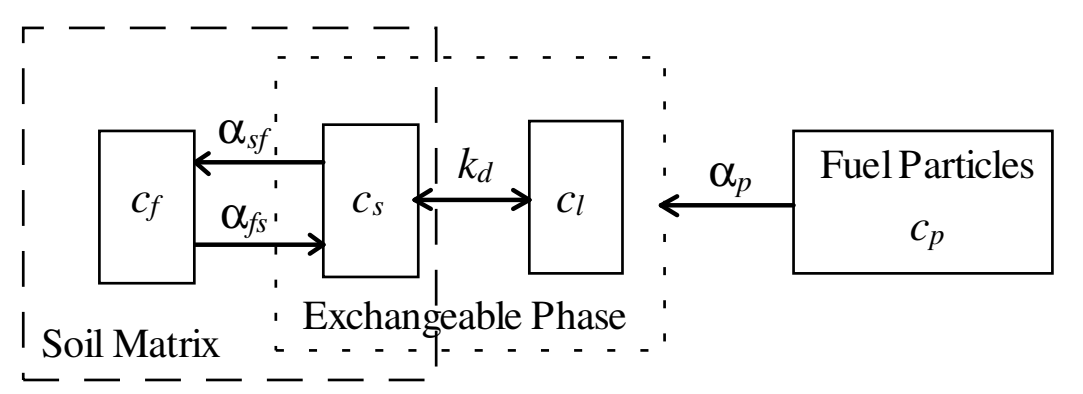

Figure 2. Schematic representation of the kinetic sorption model.

The leaching of radionuclides from the fuel particles is modelled by a first-order equation:

$$
\begin{array}{r}
\frac{\partial c_{p}}{\partial t}=-\left(\alpha_{p}+\lambda\right) c_{p}, \\
c_{p}(x, 0)=c_{p}^{0}(x),
\end{array}
$$

where $c_{p}$ is the radionuclide activity in the fuel particles per soil solid volume $\left(M L^{-3}\right) ; \alpha_{p}$ is the first-order constant of radionuclide leaching from fuel particles $\left(T^{-1}\right) ; \lambda$ is the radionuclide decay constant $\left(T^{-1}\right) ; c_{p}^{0}$ is the initial radionuclide activity in the fuel particles $\left(M L^{-3}\right)$.

Ignoring chemical diffusion in the solid phase, an equation for adjectivedispersive transport of radionuclide activity in the exchangeable phase in variably saturated media may be written in the form:

$$
\begin{array}{r}
\frac{\partial c}{\partial t}=\frac{\partial}{\partial x_{i}}\left(\phi S D_{i j} \frac{\partial c_{l}}{\partial x_{j}}\right)-\frac{\partial}{\partial x_{i}}\left(v_{i} c_{l}\right)-\lambda c+ \\
\left(1-\phi_{T}\right)\left(\alpha_{p} c_{p}+\alpha_{f s} c_{f}-\alpha_{s f} c_{s}\right),
\end{array}
$$

where $c$ is the radionuclide activity per total volume $\left(M L^{-3}\right)$.

$D_{i j}$ is the dispersion tensor defined by

$$
\phi S D_{i j}=\alpha_{T}|v| \delta_{i j}+\left(\alpha_{L}-\alpha_{T}\right) \frac{v_{i} v_{j}}{|v|}+\phi S \tau D_{0} \delta_{i j},
$$

where $\alpha_{L}$ and $\alpha_{T}$ are the longitudinal and transverse dispersiveness $(L)$, respectively; $\delta_{i j}$ is the Kronecker delta; $|v|$ is the magnitude of the Darcy velocity; $D_{0}$ is the molecular diffusion coefficient $\left(L^{2} T^{-1}\right)$; and $\tau$ is the tortuosity.

The total radionuclide activity is defined by:

$$
c=\phi S c_{l}+\left(1-\phi_{T}\right) c_{s},
$$

where $\phi_{T}$ is the total porosity of the medium; and volumetric phase activities are interrelated through the solid-aqueous partition coefficient $k_{d}$, according to the relationship

$$
k_{d}=\frac{c_{s} \rho}{c_{l} \rho_{s}},
$$


where $\rho_{s}$ is the soil solid density $\left(M L^{-3}\right)$.

Initial conditions for equation (2.2) consist of the specification of initial radionuclide activity in the aqueous phase:

$$
c_{l}(x, 0)=c_{0}(x) .
$$

Boundary conditions for inflow boundaries are Dirichlet (type 1):

$$
c_{l}=c_{1} \quad \text { on } \quad \Gamma_{3},
$$

or Cauchy (type 3):

$$
\left(-\phi S D_{i j} \frac{\partial c_{l}}{\partial x_{j}}\right) n_{i}=v_{b} c_{b} \quad \text { on } \quad \Gamma_{4},
$$

where $c_{1}$ is the prescribed radionuclide activity on the boundaries $\Gamma_{3} ; n_{i}$ is the unit vector normal to boundaries, directed inward; $v_{b}$ is the prescribed fluid flux normal to the boundaries $\Gamma_{4}$; and $c_{b}$ is the prescribed radionuclide activity associated with the prescribed fluid flux.

At outflow boundaries the assumption is often made that transport across the boundaries, according to [7], occurs by advection only and the Neumann (type 2) boundary condition is specified by

$$
\frac{\partial c_{l}}{\partial x_{j}}=0 \quad \text { on } \quad \Gamma_{5},
$$

where $\Gamma_{3}+\Gamma_{4}+\Gamma_{5}=\Gamma$ is the boundary of the domain.

The transport of activity in the fixed phase is described by:

$$
\begin{array}{r}
\frac{\partial c_{f}}{\partial t}=\alpha_{s f} c_{s}-\alpha_{f s} c_{f}-\lambda c_{f}, \\
c_{f}(x, 0)=c_{f}^{0}(x),
\end{array}
$$

where $c_{f}^{0}$ is the initial activity in the fixed phase.

\section{Simulation results}

Numerical simulations of the ${ }^{90} \mathrm{Sr}$ and ${ }^{137} \mathrm{Cs}$ migration from the Shelter into and through the subsurface environment were conducted for a twodimensional vertical cross-section selected along the streamlines of the groundwater flow. These streamlines were obtained from field observations of groundwater level distribution in the vicinity of the Chornobyl NPP [5]. The geology of this cross-section is shown in figure 3.

The MSTS code $[8,9]$ adapted to implement the model described above was used for the numerical simulations. The flow domain was discretized by a non-uniform rectangle mesh, the nodes of which were spaced at $1 \mathrm{~m}-$ $100 \mathrm{~m}$ intervals in the horizontal direction, and from 0.2 to $3 \mathrm{~m}$ in the vertical direction. Time steps of 30 days were used. Values for the hydraulic and species properties used in the simulations are given in table 1 . Values of the first-rate constants $\alpha_{s f}, \alpha_{f s}$ were taken similar to the experimentally obtained values of these parameters for the upper soil layer of the left bank floodplain of the Prypiat river. Parameters $\alpha_{s f}$ and $\alpha_{f s}$ vanished for the 


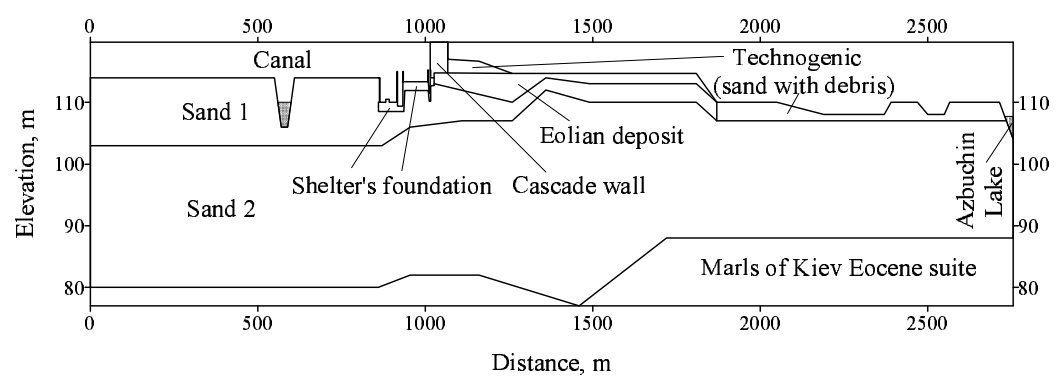

Figure 3. Schematic representation of the geologic section.

Table 1. Values of parameters used in numerical simulations.

\begin{tabular}{|c|c|c|c|c|c|c|c|}
\hline $\begin{array}{l}\text { Soil or } \\
\text { Rock }\end{array}$ & $\begin{array}{l}K \\
\mathrm{~m}_{\text {day }}{ }^{-1}\end{array}$ & $\begin{array}{c}\alpha_{L} \\
\mathrm{~m} \\
\end{array}$ & $\begin{array}{c}\alpha_{T} \\
\mathrm{~m} \\
\end{array}$ & $\begin{array}{c}k_{d}^{S r} \\
1 \mathrm{~kg}^{-1} \\
\end{array}$ & $\begin{array}{c}k_{d}^{C s} \\
1 \mathrm{~kg}^{-1} \\
\end{array}$ & $\begin{array}{c}\begin{array}{c}\alpha_{s f}^{C s} \\
\mathrm{day}^{-1}\end{array} \\
\end{array}$ & $\begin{array}{c}\alpha_{f s}^{C s} \\
\mathrm{day}^{-1}\end{array}$ \\
\hline Sand 1 & 9.0 & 1.2 & 0.1 & 1.0 & 5.2 & 0.001 & 0.00005 \\
\hline Sand 2 & 10.0 & 1.2 & 0.1 & 1.0 & 5.2 & 0.001 & 0.00005 \\
\hline Eolian deposit & 13.0 & 1.2 & 0.1 & 1.0 & 5.2 & 0.001 & 0.00005 \\
\hline Technogenic & 11.0 & 1.2 & 0.1 & 1.0 & 5.2 & 0.001 & 0.00005 \\
\hline Foundation & 0.001 & 1.0 & 0.1 & 0.5 & 5.2 & 0.001 & 0.00005 \\
\hline Cascade wall & 1.0 & 1.0 & 0.1 & 0.5 & 5.2 & 0.001 & 0.00005 \\
\hline
\end{tabular}

case of ${ }^{90} \mathrm{Sr}$ migration in the subsurface. The coefficient of radionuclide leaching from fuel particles was $3.2 \times 10^{-4}$ day $^{-1}$ [1].

The prescribed values of the hydraulic head were specified along the left and right boundaries, the top of the Shelter's foundation, and the boundaries on which surface water bodies are intercepted by the aquifer. At the ground surface the liquid flow rate was equal to the infiltration rate or evapotranspiration rate. The annual amount of infiltration was $80 \mathrm{~mm}$. The marls were considered as impervious. The water depth was assumed to be $2 \mathrm{~m}$ in the turbo-generator hall, and $1.6 \mathrm{~m}$ in rooms on the first level in the northern part of the Shelter. Seasonal fluctuations of the water level in the canal varied between $109.5 \mathrm{~m}$ and $110.2 \mathrm{~m}$; in Azbuchin Lake - between $106.0 \mathrm{~m}$ and $106.8 \mathrm{~m}$; and for the hydraulic head at the left boundary - between $109.5 \mathrm{~m}$ and $110.0 \mathrm{~m}[5]$. These seasonal fluctuations of the water level in surface water bodies and the variability over time of precipitation and evapotranspiration were taken into account in the simulations.

Before the Chornobyl accident a special drainage system operated to prevent underflooding of the Chornobyl NPP building's foundation. After the Chornobyl accident this drainage system was damaged and shut down. As a result of that a groundwater level increase was observed until 1994. The nowadays groundwater level below the Shelter varies from $109.5 \mathrm{~m}$ to $110.5 \mathrm{~m}$ depending on seasonal groundwater fluctuations and precipitation. The groundwater increase after the Chornobyl accident was not taken into account in the simulations. The initial condition for the liquid phase is illustrated in figure 4.

A zero radionuclide flux condition was employed at all the boundaries, 


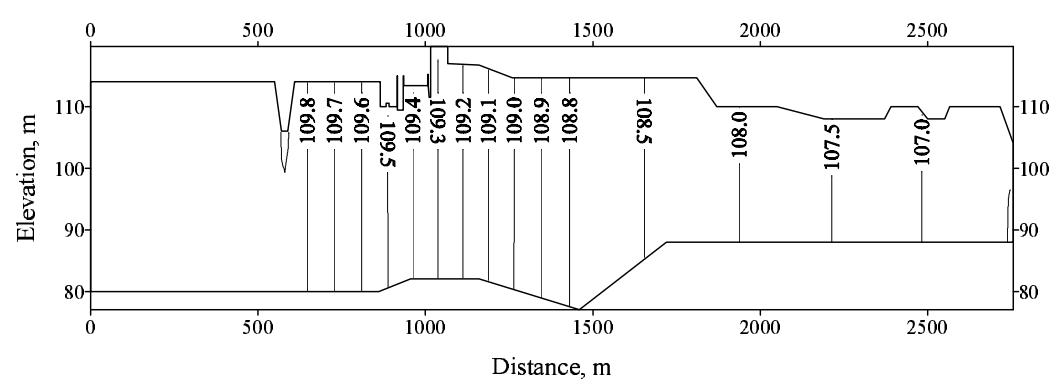

Figure 4. Initial hydraulic head distribution.

excluding the Shelter basement and the boundaries that contact surface water bodies. The ${ }^{90} \mathrm{Sr}$ activity of water from the basement was $2.3 \times 10^{6}$ $\mathrm{Bq} / \mathrm{l}$, and $2800 \mathrm{~Bq} / \mathrm{l}$ in Azbuchin Lake [5]. Similarly, ${ }^{137} \mathrm{Cs}$ activity in the basement water and Azbuchin Lake was $7.1 \times 10^{7}$ and $84 \mathrm{~Bq} / \mathrm{l}$, respectively. From 1986 to 1995 , the radionuclide activity of canal water was determined from the annual average activity of water samples from the Cooling pond. The radionuclide activity of canal water after 1995 was specified as the radionuclide activity of canal water in 1995. For the area surrounding the Chornobyl NPP, land surface contamination by ${ }^{137} \mathrm{Cs}$ in 1995 was from $3.8 \times 10^{-3}$ to $1.9 \times 10^{-4} \mathrm{Ci}$ per $\mathrm{kg}$ of soil $[2] .^{90} \mathrm{Sr}$ land surface contamination was equal to one half of ${ }^{137} \mathrm{Cs}$ and surface contamination. Just after the accident, exchangeable ${ }^{90} \mathrm{Sr}$ was $5 \%$ of the total ${ }^{90} \mathrm{Sr}$ activity and exchangeable ${ }^{137} \mathrm{Cs}$ was $10 \%$ of the total ${ }^{137} \mathrm{Cs}$ activity. The subsurface was assumed to be uncontaminated before the accident. The date of the Chornobyl accident was taken as the starting date for the simulations.

There are no reliable data on water leakage beyond the bounds of the Shelter. However, analysis of water pathways and water locations within the Shelter shows that there is a possibility of water leakage from the turbogenerator hall, northern rooms of the Shelter, and through the cascade wall. The cascade wall was filled with concrete, boxed radioactive materials collected from the roof and surroundings, building debris, and structural metals. So, it has a lot of openings and breaks through which part of precipitation onto the cascade wall penetrates into the subsurface. Therefore, in order to estimate migration rates of radionuclides from the Shelter through the subsurface, numerical simulations were conducted for the following cases:

- Case 1. Water leakage occurs from rooms on the first level in the northern part of the Shelter.

- Case 2. In addition to case 1 , one half of the precipitation onto the cascade wall penetrates into the outside of the Shelter.

- Case 3. Water from the turbo-generator hall, rooms in the northern part of the Shelter, and a half of the precipitation onto the cascade wall penetrates into the subsurface environment.

The effects of various water leakage scenarios on radionuclide migration from the Shelter through the subsurface are compared with case 2. Figures 5 and 6 show the predicted activity distribution of ${ }^{90} \mathrm{Sr}$ and ${ }^{137} \mathrm{Cs}$ radionuclides in the aqueous phase in 1995 and 2045 for case 2.

The influence of different water leakage into the outside of the Shelter on migration of ${ }^{90} \mathrm{Sr}$ through the subsurface is shown in figures 7-9. Analysis of 


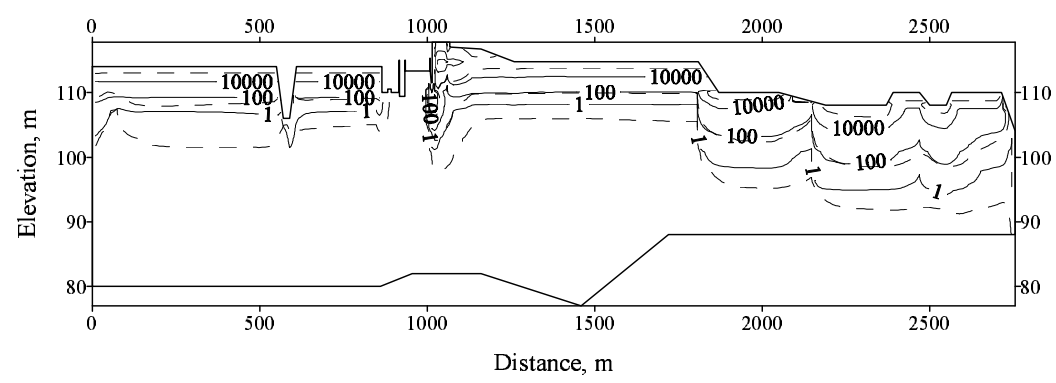

Figure 5. Activity of ${ }^{90} \mathrm{Sr}(\mathrm{Bq} / \mathrm{l})$ in the aqueous phase in (-) 1995 and (-- $) 2045$ for case 2.

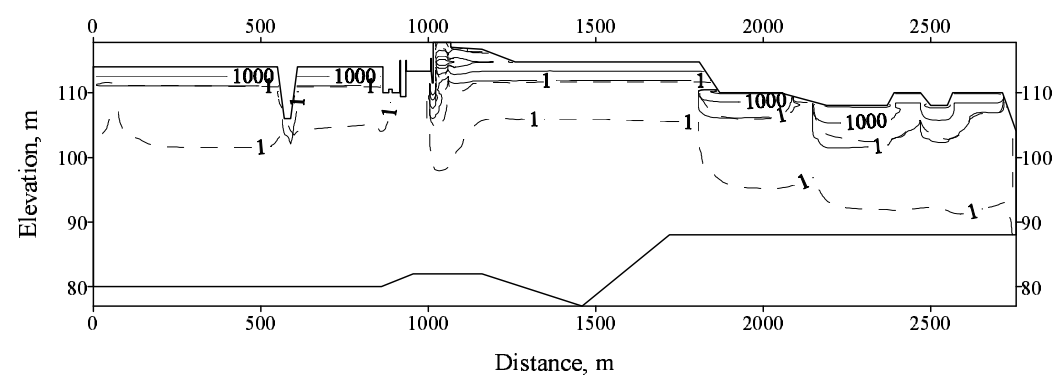

Figure 6. Activity of ${ }^{137} \mathrm{Cs}(\mathrm{Bq} / \mathrm{l})$ in the aqueous phase in $(-)$ 1995 and (-- ) 2045 for case 2.

the results indicates the increase of the groundwater level and radionuclide migration rate below the Shelter for case 3. The effect of water penetration through the cascade wall on radionuclide migration below the Shelter is negligible.

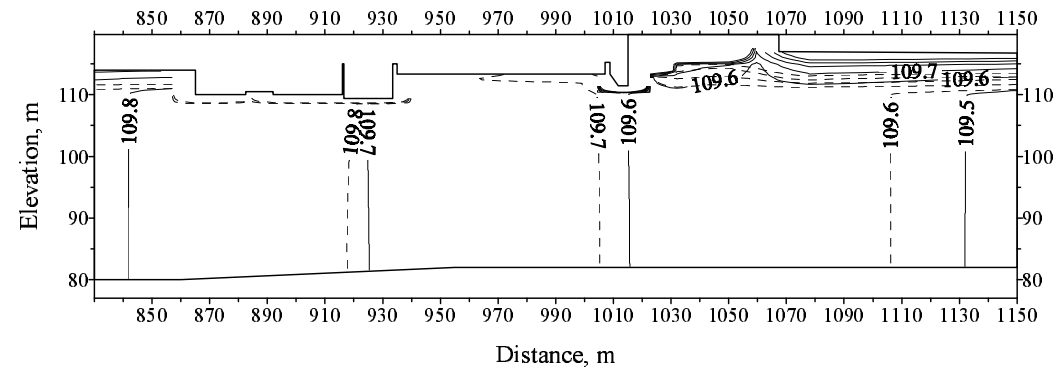

Figure 7. Summer distribution of hydraulic head below the Shelter for $(-)$ case 2 and $(--)$ case 3.

Comparisons of predicted activity-depth profiles of ${ }^{90} \mathrm{Sr}$ and ${ }^{137} \mathrm{Cs}$ radionuclides in the aqueous phase with the measurements in 1995 are given in figures 10 and 11. These predicted activity-depth profiles were selected at point $x=1075 \mathrm{~m}$ which approximately corresponds to the location of wells 1-g, 2-g and 4-g in the northern part of the Chornobyl NPP building area. The annual mean values of radionuclide activity obtained on measurements in wells 1-g, 2-g, 4-g and 6-g [2,3] are denoted by circles. A triangle denotes the radionuclide activity detected in well C10 in 1995 [5]. Well C10 


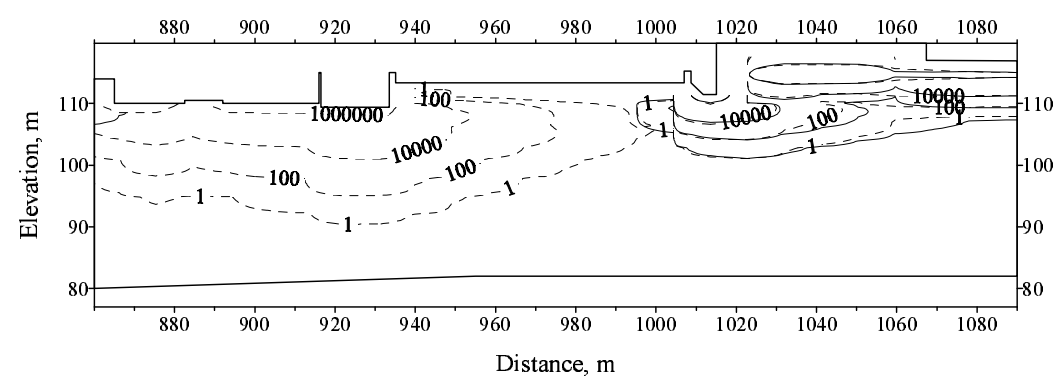

Figure 8. Activity of ${ }^{90} \mathrm{Sr}(\mathrm{Bq} / \mathrm{l})$ in the aqueous phase below the Shelter in 1995 for (-) case 2 and (--) case 3.

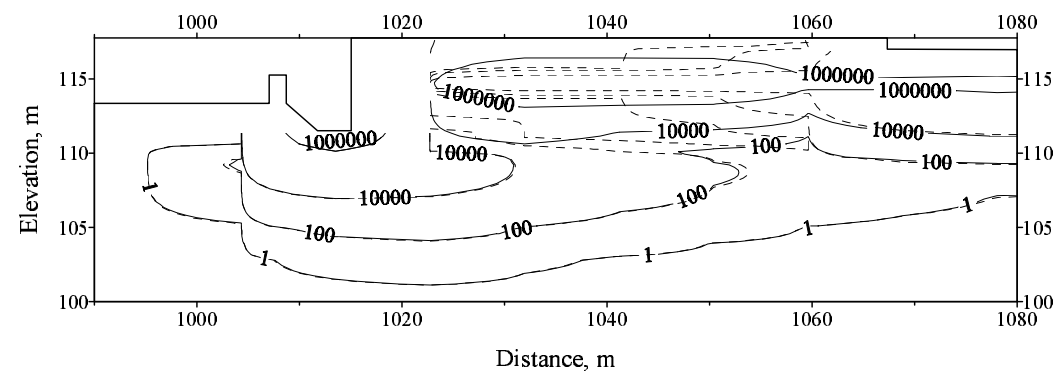

Figure 9. Activity of ${ }^{90} \mathrm{Sr}(\mathrm{Bq} / \mathrm{l})$ in the aqueous phase below the Shelter in 1995 for $(-)$ case 2 and (--) case 1.

Aqueous activity $(\mathrm{Bq} / \mathrm{l})$ of $\mathrm{Sr}-90$

$1 \mathrm{E}-5 \quad 1 \mathrm{E}-4 \quad 1 \mathrm{E}-3 \quad 1 \mathrm{E}-2 \quad 0.1 \quad 1 \quad 1 \mathrm{E}+11 \mathrm{E}+21 \mathrm{E}+31 \mathrm{E}+41 \mathrm{E}+51 \mathrm{E}+61 \mathrm{E}+7$

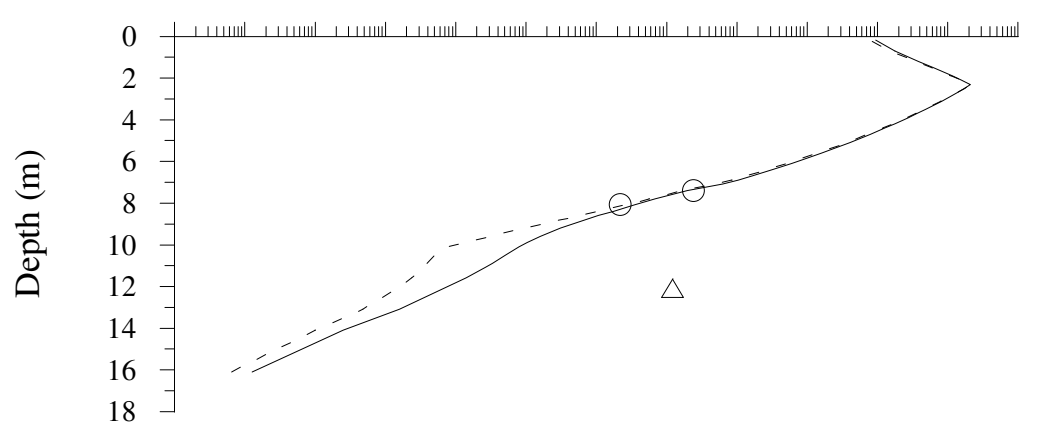

Figure 10. Comparison of predicted and measured activity-depth profiles of ${ }^{90} \mathrm{Sr}$ in the aqueous phase in 1995 . Modelgenerated profiles were obtained for $(-)$ case 2 and $(--)$ case $3 . \triangle$ and $\bigcirc$ denote mean values of radionuclide activity detected in well $\mathrm{C} 10$ and in wells $1-\mathrm{g}, 2-\mathrm{g}, 4-\mathrm{g}$ and 6 -g, respectively. 
Aqueous activity $(\mathrm{Bq} / \mathrm{l})$ of $\mathrm{Cs}-137$

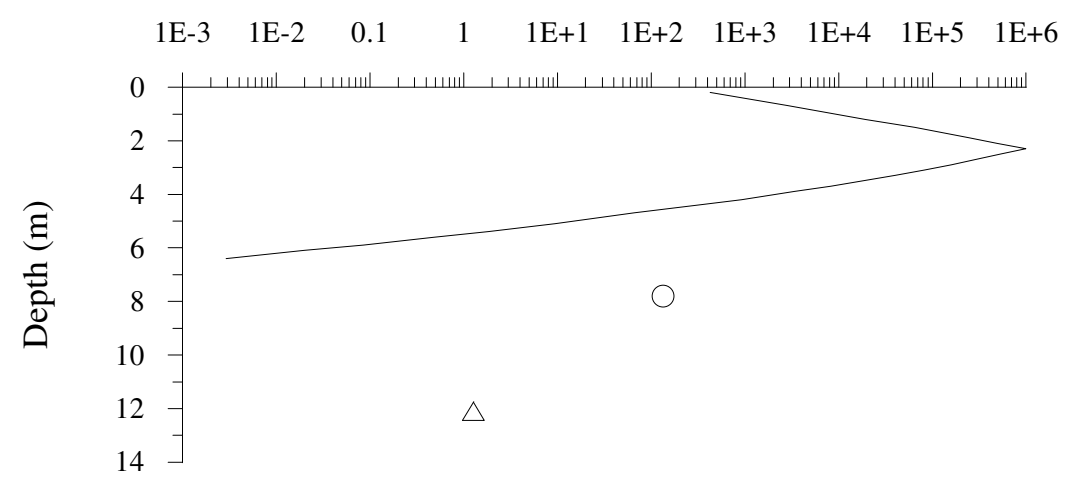

Figure 11. Comparison of predicted and measured activity-depth profiles of ${ }^{137} \mathrm{Cs}$ in the aqueous phase in 1995. Modelgenerated profile was obtained for $(-)$ case $2 . \triangle$ and $\bigcirc$ denote mean values of radionuclide activity detected in well C10 and in wells 1-g, 2-g, 4-g and 6-g, respectively.

is located approximately $150 \mathrm{~m}$ east of wells $1-\mathrm{g}$ and 4 -g.

\section{Conclusions}

This work has concentrated on modelling ${ }^{90} \mathrm{Sr}$ and ${ }^{137} \mathrm{Cs}$ migration from the Shelter into and through the subsurface environment. A two-dimensional mathematical model accounting for the coupled transport of water and radionuclides in variably saturated porous media was used. The hydraulic conductivity, the longitudinal and transverse dispersiveness are sensitive parameters for radionuclide transport modelling. The key parameters for radionuclide exchange between soil water and soil matrix are the distribution coefficient or $k_{d}$, and first-order rate constants $\alpha_{s f}$ and $\alpha_{f s}$. Due to the limited availability of field data, these parameters were assigned by experts. As a result of that only a qualitative radionuclide transport modelling was achieved. However, modelling results presented in this work illustrate the basic effects of different possible water leakage into the outside of the Shelter on the migration rate of radionuclides through the subsurface. The simulation results showed that, so far, the groundwater contamination detected in the observation wells is only defined by the surface land contamination. Much more quantitative testing must be conducted to evaluate the environmental impact of the Shelter on the subsurface contamination.

\section{Acknowledgements}

I am grateful to Mark D. White and Will E. Nichols from the Pacific Northwest National Laboratory, Battelle, Richland, WA, USA, for their permission to use the computer code MSTS in modelling the subsurface contamination by radionuclides. 


\section{References}

[1] Chornobyl accident. Edited by V.G.Baryakhtar. Kiev, Naukova Dumka, 1995 (in Russian).

[2] Borovoi A.A, Evstratenko A.S., Krinitsyn A.P., Matyukhin A.P., Pavlyuchenko N.I., Simanoskaya I.Ya., Khorenko I.P. Shelter radioactive condition dynamics. / Shelter - 10 years. Main scientific research results. Chornobyl, Interdisciplinary Scientific and Technical Centre "Shelter", National Academy of Sciences of Ukraine, 1996, p. 100-111 (in Russian).

[3] Pavlyuchenko N.I., Khorenko I.P. Review of works to study technogeologic section and radionuclide contamination of groundwater for building area of the Shelter. // Problems of the Exclusion Zone, 1996, No 3, p. 58-65 (in Russian).

[4] Selection and feasibility study of safety technology for removal of nuclearhazard fission materials from rooms of accidentally destroyed unit-4 of the Chornobyl NPP on base of developed industrial technologies. Analysis and generalization of known data. Chornobyl-Kiev, State Company "Technocentre" for Treatment and Disposal of Mixed Hazardous Waste Report, No 01974006587, 1997 (in Russian).

[5] On-going and predictive estimations of radiogeologic condition changes of the exclusion zone. Development of recommendations for improvement of groundwater monitoring. Kiev, Institute of Geologic Sciences Report, No 0195V022415, 1995 (in Russian).

[6] Konoplev A.V., Kopylova L.P., Bobovnikova Ts.I., Bulgakov A.A., Siverina A.A. Distribution of ${ }^{90} \mathrm{Sr}$ and ${ }^{137} \mathrm{Cs}$ within the system of bottom sediments-water of the reservoirs in the areas adjacent to the Chornobyl NPP. // Meteorologiya i Gidrologiya, 1992, No 1, p. 35-42 (in Russian).

[7] Frind E.O. Simulation of long-term transient density-dependent transport in groundwater. // Adv. Water Resour., 1982, No 5, p. 73-86.

[8] White M.D., W.E.Nichols. MSTS: multiphase subsurface transport simulator. Theory manual. Richland, Washington, USA, Pacific Northwest Laboratory, PNL-8636, 1992.

[9] White M.D., W.E.Nichols, MSTS: multiphase subsurface transport simulator. User's guide and reference. Richland, Washington, USA, Pacific Northwest Laboratory, PNL-8637, 1993.

\section{МАТЕМАТИЧНЕ МОДЕЛЮВАННЯ ПЕРЕНОСУ РАДІОНУКЛІДІВ У ПРИПОВЕРХНЕВОМУ СЕРЕДОВИЩІ НАВКОЛО ЧОРНОБІЛЬСЬКОЇ АЕС}

\section{С.Л.Ківва}

Саркофаг, що споруджено над зруйнованим четвертим блоком Чорнобильської АЕС, містить 20 МКи ядерного палива. Більш ніж $1000 \mathrm{~m}^{3}$ середньоактивної води знаходиться на його нижніх поверхах. Метою даної роботи було моделювання міграції радіонуклідів ${ }^{90} \mathrm{Sr}$ та ${ }^{137} \mathrm{Cs}$ з Саркофагу в геологічне середовище для оцінки іх швидкості та шляхів міграції. Для цього використовувалась сумісна модель руху вологи та радіонуклідів в насичено-ненасиченому пористому середовищі. Недостатня кількість польових і лабораторних досліджень не дозволила повністю верифікувати модель. Результати моделювання можуть бути використані в подальших дослідженнях 3 оцінки впливу Саркофагу на забруднення оточуючого середовища. 